Revista de Economia Política, vol. 29, n 2 (114), pp. 267-284, abril-junho/2009

\title{
Existe uma ordem econômica internacional? A problematização de uma premissa
}

\author{
DAWISSON BELÉM LOPES \\ LEONARDO CÉSAR SOUZA RAMOS*
}

Is there an international economic order? This article invites to a reflection on the ontological and axiological foundations of the concept 'international economic order'. We argue that the notion of 'order' implies, at first, identifying a sort of social arrangement or pattern. However, as we intend to demonstrate, this pattern is hardly present in contemporary international economic relations. Besides, the adjectives 'economic' and 'international' instill doubt not only in regard to the nature of the 'international', but also in what concerns the feasibility of spotting a working pattern in international economy nowadays. Thus, it seems, on heuristical terms, an appropriate methodological option to revisit some of the main canonical contributions to the theme of international (economic) order, and to submit it to academic scrutiny. Additionally, we seek to evaluate how plausible it is to think of a 'multilateral' economic international order.

Keywords: international political economy; order; multilateralism; international relations.

JEL Classification: F02; F50; F55.

\footnotetext{
* Professor de Relações Internacionais do Centro Universitário de Belo Horizonte (UNI-BH). e-mail: dawisson@gmail.com, e Professor de Relações Internacionais do Centro Universitário de Belo Horizonte (UNI-BH). E-mail: lcsramos@yahoo.com.br. Uma versão preliminar deste trabalho foi apresentada no "I Encontro Nacional da Associação Brasileira de Relações Internacionais" (Brasília-DF, 26 de julho de 2007), sob o Painel "Instituições e Economia Global”. Os autores agradecem imensamente os comentários feitos, à ocasião, pela professora Ana Maria Stuart e membros da audiência - dos quais esta versão final do texto se beneficiou. Como de praxe, os autores assumem inteira responsabilidade por todas as carências e limitações que o artigo, porventura, conserve. Submetido: Agosto 2007; Aprovado: Dezembro 2007.
} 
"If, as has been suggested, terminology is the properly poetic moment of thought, then terminological choices can never be neutral."

Giorgio Agamben ${ }^{1}$

\section{INTRODUÇÃO}

Este artigo suscita uma reflexão mais detida sobre os fundamentos ontológicos e axiológicos em que assenta a noção de "ordem econômica internacional". Conforme se argumentará, a expressão ordem econômica internacional carrega em si os germes da controvérsia. A evocação de uma ordem pressupõe um tipo de arranjo social identificável por um observador, esteja ele socialmente imerso ou (pretensamente) alheio à dinâmica social. Porém, tentaremos demonstrar que esse padrão não é facilmente apreensível nas relações econômicas internacionais contemporâneas. Além disso, a qualificação dessa ordem como econômica e internacional gera dúvidas, relativas tanto à natureza do "internacional” em questão quanto à própria viabilidade empírica de uma forma de ordenamento da economia internacional. Assim, parece produtivo, do ponto de vista heurístico, retornar a algumas das contribuições canônicas mais relevantes sobre o tema da ordem (econômica) internacional, submetendo-as a escrutínio. Adicionalmente, avaliaremos se é plausível pensar em uma ordem econômica internacional multilateral.

\section{A NOÇÃO DE ORDEM INTERNACIONAL}

Etimologicamente, ordem remete ao latim ordo, ou seja, a um arranjo ou disposição (Saraiva, 2006: 826). A ordem é, pois, o padrão que se pode identificar a partir de um determinado ponto de vista. As mitologias e teogonias ocidentais sempre valorizaram essa ideia - tanto assim que a própria Bíblia, a mais remota das encadernações, traz em seu livro da "Gênese", no Antigo Testamento, menção à construção do mundo, a qual culmina com a descrição do Paraíso, símbolo da ordem perfeita; e aos episódios em que a harmonia suprema se teria desfeito - bastando, como síntese do alegado, as narrativas da Culpa Original e da Torre de Babel. Do caos, por intervenção divina, fez-se a ordem; da ordem, pela ação humana, tornou-se ao caos.

No terceiro livro da República, Platão contemplou o tema da ordem (política). Porém, a sua contribuição à questão aqui problematizada é tópica. Para

\footnotetext{
${ }^{1}$ Agamben, G. State of Exception. Tradução de Kevin Attell. Chicago: The University of Chicago Press, 2005 , p. 4 .
} 
tentar explicar o fenômeno da permanência a despeito dos fluxos, o pensador lançou mão da expressão "ritmo". Ritmo é a ordem em movimento, ou, no contexto do citado diálogo, aquilo que põe o canto e a música em relação harmoniosa com os movimentos corporais (Platão, 2001). De relevante, fica sugerido que a natureza de uma ordem não é necessariamente estática. Antes, pode acontecer de um padrão que, embora dinâmico, seja perfeitamente identificável, contínuo e coerente.

No relativo às relações internacionais, parece aconselhável conceber "ordem” como equilíbrio dinâmico, dada a profusão de movimento que caracteriza o mundo contemporâneo. Numa chave moderna, ter-se-ia menos escrúpulo de afirmar que a ordem é uma criação humana - ou, para ser mais preciso, uma instituição social. Toda ordem é construída e, enquanto tal, falível, inacabada, precária. Desde Maquiavel - que avista no trio pax, ordo et concordia a missão do príncipe -, passando por Hobbes e o imperativo da ordem absolutista como negação do "estado de natureza", uma plêiade de autores pôs-se a teorizar sobre qual seria o arranjo ideal para a boa convivência humana (Wolin, 1960).

Nas relações internacionais, a instituição da ordem internacional é, sem dúvida, um dos principais objetos de estudo da teoria do pós-Segunda Guerra - tendo motivado incursões as mais variadas, amparadas em pressupostos valorativos e metodológicos diversos. A recorrência do tema entre nós chega a sugerir a existência de "ideólogos da ordem", isto é, pensadores capazes de delinear e/ou dispostos a reproduzir um conjunto de valores, práticas e esquemas organizacionais por via de elaborações discursivas. A eles tem-se concedido o epíteto de "canônicos". Deles nos ocuparemos, em sequência.

Contudo, uma discussão lançada por Robert Cox (1996) é digna de rápida apreciação, antes de colocarmos em revista as contribuições do cânone sobre o tema em voga. Cox questiona se, de fato, aquilo que se há de reivindicar é a existência de uma ordem internacional ou mundial. Isso porque, a rigor semântico e histórico, o "internacional" na modernidade referiu-se originalmente ao jogo entre os Estados territoriais soberanos (Walker, 1993) - o que excluiria, de saída, uma série de relações internacionais que se dão para além e aquém dos Estados. Essa intensa atividade internacional não-estatal seria mais bem captada, para Cox, com o emprego da expressão "ordem mundial", ao que esta se lhe afigura mais inclusiva e abrangente. No mérito da argumentação, o autor parece estar com a razão. Mas a contra-argumentação que queremos oferecer-lhe, respaldados por considerável produção literária recente (Biersteker; Hall, 2002; Kahler; Lake, 2003; Ong, 2006), é de que o "internacional" contemporâneo não pode estar circunscrito às relações entre Estados ou governos. Antes, ele deve abarcar as organizações não governamentais, as empresas multinacionais, os grupos terroristas, as máfias, as lideranças municipais, os grupos de pressão cibernéticos, as agências de classificação de risco país, os indivíduos, dentre outros novos atores. Logo, as expressões 
“ordem internacional" e "ordem mundial" serão consideradas, para os efeitos pretendidos por este ensaio, intercambiáveis entrei si. ${ }^{2}$

Para conseguir mapear o estado da arte no tocante ao tema da ordem internacional, cumpre fazer breve resgate de algumas das elaborações canônicas.

Bull e Escola Inglesa. Em "The Anarchical Society: A Study of World Order" [1977], Hedley Bull apresenta a sua concepção de ordem mundial. Para tanto, parte da ideia de que o tipo de ordem buscado pelos homens não é uma regularidade qualquer para o convívio entre indivíduos, mas um padrão específico, conducente a um resultado particular. A ordem social de Bull é o arranjo que promove um certo conjunto de valores elementares, primários ou universais. São eles: a vida, a verdade e a propriedade. Por suposto, quando alude à ordem internacional, Bull faz menção ao "padrão de atividade que dá sustentação aos objetivos primários de uma sociedade de Estados" (Bull, 1995: 8).

Antes de explicar os elementos constituintes da ordem internacional, importa atentar para a distinção feita pelo autor entre sistema de Estados (ou sistema internacional) e sociedade de Estados (ou sociedade internacional). Por sistema internacional, pretende-se a formação resultante das interações repetidas e mais ou menos constantes entre dois ou mais Estados, que tenham capacidade que afetar as decisões do outro, de modo que cada unidade estatal se comporte como se fosse parte integrante de um todo mais amplo. Nepal e Bolívia, por exemplo, podem compor um mesmo sistema de Estados sem que, necessariamente, um afete diretamente as ações do outro. Já a sociedade internacional existe quando os Estados, conscientes de determinados interesses e valores comuns, formam uma sociedade, no sentido de se reconhecerem vinculados por um mesmo conjunto de regras nas suas relações uns com os outros, e de compartilharem instituições comuns. Donde a alegação bulliana de que uma sociedade internacional pressupõe um sistema internacional, embora o oposto não seja acertado dizer (Idem).

Passemos, então, em revista as alegadas metas primárias da sociedade internacional: (1) a preservação do sistema e da sociedade de Estados per se; (2) a manutenção da independência política ou soberania externa dos Estados; (3) a manutenção das promessas e a estabilização da posse por meio de regras; e (4) o estabelecimento de uma paz duradoura. A ordem na política mundial só se materializará por completo quando houver disposição de defender as metas elementares da vida social numa escala mundial, conformando-se uma grande sociedade para toda a humanidade (Ibidem).

Waltz e Neo-realismo. Kenneth Waltz, pai fundador do neo-realismo nas relações internacionais, apresenta as suas formulações sobre a ordem internacional em duas obras clássicas: "Man, the State, and War" [1959] e "Theory of International Politics" [1979]. Naquela, Waltz estipulou (no auge da guerra fria) uma

\footnotetext{
${ }^{2}$ Em que pesem as suas peculiaridades semânticas, de que estamos plenamente conscientes.
} 
classificação essencialista do mundo em três níveis ou "realidades básicas", quais sejam: (1) a natureza do homem, concebida em termos hobbesianos; (2) a natureza dos Estados, que, embora difiram em sua constituição interna, carregam consigo uma concepção muito assemelhada do interesse nacional (estatal); e (3) a natureza do sistema internacional, que, à ausência de um Leviatã para reger as interações entre as suas unidades políticas básicas (os Estados), atinge a situação de equilíbrio não por meio de constrangimentos racionais, e sim pela instituição da "balança de poder" (Waltz, 2004).

A consequência da semente lançada em 1959 é a obra magna de Waltz, "Theory of International Politics", publicada vinte anos mais tarde. Nela, o autor cristaliza suas ideias sobre a constituição da ordem internacional, apresentando os principais pontos do seu neo-realismo. Waltz naturaliza a ideia do conflito, na medida em que argumenta ser a ordem internacional o resultado das medições de força entre as suas unidades constituintes, os Estados. Embora a estrutura do sistema internacional waltziano seja horizontal, porquanto anárquica, existe hierarquia decorrente da distribuição de capacidades materiais [capabilities] entre os Estados, que se lançam irremediavelmente no esforço para sobrepujarem uns aos outros. Ao cabo, essa hierarquia acaba limitando e constrangendo o exercício da soberania pelos Estados mais fracos (Waltz, 1979).

A ordem internacional neo-realista, portanto, delineia-se a partir da observação de certas regularidades duradouras na conduta dos (e entre os) Estados. São elas, em termos gerais: (a) os interesses do governante, e então do Estado, determinam o curso de ação; (b) as necessidades da política emergem da competição desregulada entre Estados; (c) o cálculo racional baseado nessas necessidades leva às políticas que melhor servirão aos interesses do Estado; (d) o êxito é o teste derradeiro de uma política; e (e) e esse sucesso é medido em termos de preservação e fortalecimento do Estado (Idem).

Doyle e (Neo)liberalismo. Numa apropriação extemporânea da tese kantiana da paz democrática, Michael Doyle (1999) advoga por uma comunidade de Estados “autenticamente liberais”, dada a característica inerente a regimes democráticos de respeitar e dialogar com outros países democráticos antes de recorrer ao conflito. Há uma considerável ruptura substantiva com o racionalismo da vertente neorealista, uma vez que se supõe a substituição dos mecanismos da balança de poder e da guerra por instituições conducentes à maior cooperação entre os Estados, como o direito internacional e as organizações internacionais, além do incentivo ao livre-mercado e à promoção dos proverbiais "valores democráticos". Ainda dentro desse raciocínio, uma ordem internacional liberal requer uma espécie de “cruzada”, isto é, a mobilização dos “verdadeiros” Estados democráticos para preservar e expandir a comunidade liberal.

A ideia de preservação relaciona-se com o objetivo de "proteger a comunidade e gerenciar e mitigar as tensões normais entre economias de mercado liberais" (Doyle, 1999: 42). Já a expansão - que presume a proteção - parte do reconheci- 
mento da inadequação de estratégias estatais ofensivas, na medida em que pretende promover a articulação do Estado com a sociedade civil, cabendo a esta inspirar e instigar o processo de liberalização/democratização mundo afora; e àquele, intervir em favor desse objetivo, se e quando necessário. Os fundamentos axiológicos da noção de ordem internacional liberal de Doyle são os seguintes: (1) ou os povos se libertarão ou se modernizarão; (2) pela lógica kantiana, contatos transnacionais e da mobilização militar levarão a pressões internas de democratização; e (3) devem ser estipulados critérios objetivos e subjetivos para a comunidade liberal julgar quando um povo deve ser "ajudado" (Idem).

Wallerstein e (Neo)marxismo. Partindo do conceito de sistema-mundo, Immanuel Wallerstein vê o sistema internacional como uma estrutura que se encontra integrada sob a lógica da acumulação capitalista. Nessa estrutura, aconteceria o processo de exploração dos países pobres ou periféricos pelos países centrais. Como o autor parte de uma análise sistêmica, a sua atenção volta-se para o processo de acumulação e como este se organiza no tempo e no espaço. Ou seja: como o sistema evolui ao longo do tempo a partir da busca, pelo capital, de regiões nas quais ele seja mais valorizado.

No contexto de organização e reorganização espacial do sistema-mundo, observa-se um concomitante processo de deslocamento geográfico dos centros de poder econômico mundial. É em função dos ciclos de expansão e de declínio econômico que se dá tal deslocamento, o que aponta para uma questão fundamental em Wallerstein, a saber: as mudanças na distribuição de poder no sistema internacional estão diretamente ligadas ao movimento do capital em escala global.

Essa organização espacial do sistema-mundo decorrente do movimento do capital produz uma estratificação entre os Estados, baseada na concentração espacial do capital. Assim, os Estados podem dividir-se em centrais, semiperiféricos ou periféricos, sendo que tal classificação diz respeito - e tem desdobramentos - tanto à concentração e localização das atividades econômicas mais ou menos intensivas em capital e mão-de-obra, quanto à organização e institucionalização política dos Estados. Logo, combinando uma perspectiva marxista acerca das contradições do capitalismo com uma análise da dimensão política das relações internacionais, Wallerstein entende a ordem internacional como sendo permeada por contradições econômicas e políticas, no que a exploração dos países periféricos pelos centrais é crucial para a reprodução do sistema mas, ao mesmo tempo, fomentadora da crise desse mesmo sistema (Wallerstein, 1979, 1996).

Cox e Teoria Crítica. ${ }^{3}$ Para Robert Cox, os padrões das relações de produção seriam o ponto de partida para a análise tanto da operação quanto dos mecanismos de hegemonia. Destarte, mediante o conhecimento dos diferentes modos de relações

\footnotetext{
${ }^{3}$ Entendemos que a teoria crítica não deve ser considerada "canônica", numa acepção forte do termo, e, sim, uma "escola" ou "corrente" de pensamento na disciplina acadêmica das Relações Internacionais.
} 
sociais de produção, é possível identificar como processos cambiantes de produção dão lugar a forças sociais particulares, que se tornam as bases do poder tanto dentro quanto através dos Estados, bem como dentro de uma ordem mundial específica.

A relação entre produção e poder é fundamental em Cox. O autor analisa como o poder nas relações sociais de produção pode dar origem a certas forças sociais; como as forças sociais podem tornar-se a base do poder nas formas de Estado; e como as formas de Estado podem moldar a ordem mundial. Especificamente, seriam três as esferas de atividade que constituem uma estrutura histórica: (1) a organização da produção - as forças sociais engendradas pelo processo de produção; (2) as formas de Estado - os complexos "Estado/sociedade civil" historicamente contingentes; (3) as ordens mundiais - as configurações particulares de forças que definem sucessivamente a problemática da guerra e da paz. Consequentemente, pode-se representar o processo histórico por meio de uma configuração particular das estruturas históricas. Não há um relacionamento unilateral entre as três esferas de atividade e o prisma para explicar o processo histórico pode variar. Além disso, dentro de cada uma das três esferas, há três outros elementos que se combinam dialeticamente para constituir uma estrutura histórica: (1) ideias - significados intersubjetivos e imagens coletivas sobre a ordem mundial; (2) capacidades materiais - recursos acumulados; (3) instituições - o amálgama entre os dois elementos anteriores. Cox desenvolve esse quadro de análise a fim de perscrutar as estruturas históricas que têm existido temporalmente, dentro do sistema capitalista de produção. Seu suposto analítico é a ordem mundial, e é a partir desse ponto que a noção de hegemonia começa a desempenhar um papel em seu arcabouço teórico (Cox, 1986).

Notar que, em nenhum momento, nas elaborações do cânone aqui sumarizadas, se deu a dissecação da ideia de ordem econômica internacional. Se as formulações teóricas dominantes na disciplina acadêmica das Relações Internacionais mostram-se superficiais ou omissas, passando ao largo de especificidades do construto "ordem internacional", cabe, a partir dessa constatação, identificar quais seriam, ex hypothesi, os traços propriamente econômicos de uma (suposta) concertação internacional. Assim, proporemos uma definição de "ordem econômica internacional" a contrapelo, via processos de conjectura e refutação - ou seja, conforme o método hipotético-dedutivo. Acredita-se que, uma vez feita a análise dos itens que pretensamente compõem tal ordem, se poderá inferir se existe (ou não) um padrão organizacional consistente - qualquer que seja ele - na economia política internacional contemporânea.

\section{O QUE CARACTERIZA UMA ORDEM "ECONÔMICA" INTERNACIONAL? ALGUNS APONTAMENTOS}

Não obstante a flagrante dificuldade para definir a ordem (econômica) internacional, têm sido produzidos - desde há muito - diagnósticos a respeito da exis- 
tência dessa ordem. De Karl Marx a Pierre Bourdieu, de Max Weber a Anthony Giddens, de Émile Durkheim a Richard Sennett, de Talcott Parsons a John Ruggie, economistas e sociólogos vêm tentando oferecer caracterização de um padrão de atividade econômica que se constata no nível internacional (ou global), a despeito do caráter não-orgânico e assistemático dessas incursões.

O propósito desta parte da investigação é coligir algumas dessas formulações, de modo a dar-lhes coesão e unidade. Já descontada, de antemão, a artificialidade de toda e qualquer segmentação das relações internacionais, ainda assim recorreremos a esse expediente, na medida em que há reconhecido valor heurístico na estratégia metodológica de decompor o objeto de análise. Por ora, suspenderemos o juízo acerca da (im)propriedade de falar-se em ordem econômica internacional, ou mesmo da viabilidade de apontar-se um "campo econômico" (Bordieu), um tipo de "ação econômica" (Weber) ou um perfil antropológico de homo oeconomicus. Deliberadamente, abordaremos a questão em tela sob a forma de tópicos, ao que se seguirá, ao fim da exposição, a nossa tentativa de elaborar uma conclusão sobre a plausibilidade de uma ordem econômica internacional.

Divisão internacional do trabalho. Se o liberal Adam Smith foi quem primeiramente aventou uma divisão internacional do trabalho, em pleno século XVIII, baseada na noção de "vantagens absolutas" que os Estados poderiam auferir via comércio internacional - posteriormente transformada, por David Ricardo, na teoria das vantagens comparativas -, o primeiro pensador a problematizá-la foi Marx, já no século XIX. Tanto que a sua ideia de alienação do trabalhador no processo produtivo foi, oportunamente, reapropriada por ditos "neomarxistas", e transportada para a análise das relações econômicas internacionais. Teóricos proponentes do esquema "centro-periferia" ou do "sistema-mundo" alegam, guiados por abordagens estruturalistas, haver uma assimetria incrustada nas relações econômicas internacionais. As unidades "centrais" seriam os Estados mais desenvolvidos e poderosos, os quais submeteriam a periferia internacional às suas necessidades - como se ela, a periferia, fosse o complemento conveniente de uma grande cadeia produtiva global, provendo insumos de baixo valor agregado. Durkheim, outro pensador seminal do século XIX, debruçou-se sobre esta questão - vide a obra "A divisão do trabalho na sociedade" [1893]. O seu argumento é eminentemente sociológico; ele não está preocupado com a divisão do trabalho em termos de eficiência (como os liberais), e sim com a capacidade que tal divisão tem de gerar a coesão social. É no bojo dos estudos sobre a divisão do trabalho que o autor avança as noções de solidariedade "mecânica" e "orgânica", bem como a percepção de que, se a atividade econômica de uma sociedade não fosse regulada por critérios morais e legais, tender-se-ia à anomia (uma patologia social resultante do desencontro entre as práticas e a falta de regulação). Se vertido para o contexto das atuais relações econômicas internacionais, o padrão anômico durkheimiano poderia verificar-se, por exemplo, quando das crises financeiras internacionais. Diante do fenômeno mundial da carência de empregos, Sennett 
(2006) sugere adotar-se a "solução holandesa" (partilha de empregos; redução de jornadas; mobilização de toda a população economicamente ativa) - que se pode dizer derivada - guardadas as inúmeras modulações supervenientes - do diagnóstico de Durkheim. Porém, por outro lado, é ainda bastante difícil imaginar uma concepção de solidariedade orgânica mundial transplantada para o contexto de uma pretensa ordem econômica internacional.

A relação entre a economia, a sociedade e o (sistema de) Estado(s). O pensador, por excelência, das modernas relações entre economia, sociedade e Estado é Weber (1997). A grande novidade por ele trazida ao campo da reflexão consiste na subversão que promove do ideário de Marx, já que defende a autonomia das esferas econômica e política - diferentemente do materialismo marxiano. A própria ação econômica, dirá Weber, é social, porque carregada de sentido. Assim, para além da dimensão material da existência, Weber considerará as estruturas ideacionais - e.g., as instituições políticas. Outra fundamental contribuição weberiana é a teorização do mercado como instituição promotora da racionalização econômica e da socialização de indivíduos anônimos. Esse mercado - em escala nacional ou internacional - demandará um Estado (ou conjunto de Estados) para regular as interações entre os atores sociais. Numa chave parsoniana, tal relação torna-se mais esquemática, uma vez que a função da economia (um dos subsistemas sociais) está previamente dada: resolver o problema da adaptação de uma sociedade ao seu meio. Ou seja: há manifesta ascendência da categoria "social" sobre a "econômica" e a "política", na medida em que estas se subsumem (funcionalmente) naquela. Karl Polanyi (2000) admite que, embora por longa data se tenha acreditado na capacidade auto-regulatória do mercado (desde o início do século XIX, pelo menos), a lição legada pela crise do entreguerras (século XX) foi a da imprescindibilidade do Estado como ator político, capaz de corrigir rumos e evitar o autoestrangulamento do capitalismo contemporâneo. A sua tese do "duplo movimento" (a reação da sociedade à utopia das leis de mercado) continua a inspirar autores contemporâneos. Cox, por exemplo, argúi: "In the late twentieth century, we can discern a similar recurrence of the double movement. A powerful globalizing economic trend thrusts toward the achievement of the market utopia on the global scale. At the present moment, the protective response of society appears to be less sure, less coherent. Yet the elements of opposition to the socially disruptive consequences of globalization are visible" (Cox, 1996: 155).

O substrato liberal da economia internacional. Weber (1997) foi dos primeiros a atestar a racionalização das relações humanas por meio da imagem-metáfora do "desencantamento de mundo". O perfil antropológico do homem racional, nos termos econômicos da expressão, data de fins do século XIX (influência direta do utilitarismo anglo-saxão). Antes ainda, porém, no século XVIII, lançaram-se algumas das ideias-força mais poderosas da história recente. A referência óbvia aqui é o liberalismo, e sua advocacia do indivíduo, em detrimento de categorias coletivas. Esse liberalismo manifesta-se diferentemente nas várias searas. Materializa-se nos 
valores da liberdade de credo e de convicção, liberdade de expressão e de imprensa, liberdade de locomoção, entre outros. Mas é na economia, principalmente, que o liberalismo aparece de forma mais palpável. Fala-se recorrentemente no mercado livre, na livre iniciativa, na livre concorrência, na livre remessa de lucros, e em outras formas de se repelir o controle social/estatal da atividade econômica. No rastro de Polanyi, John Ruggie (1983) sustentará a tese de que, desde o ocaso da Segunda Guerra, tem-se dado o fenômeno do "liberalismo incrustado" [embedded liberalism]. Para Ruggie, existe um substrato liberal na ordem econômica internacional, fruto de um consenso atingido entre os principais vencedores da Grande Guerra (ênfase maior nos Estados Unidos da América e na Inglaterra). Na base dessa ordem haveria uma confluência entre a estrutura material de poder (as instituições propriamente ditas, como ONU, FMI, Banco Mundial, GATT/OMC, OCDE) e um "propósito social legítimo". Um pouco diferentemente da versão original, o neoliberalismo, variante contemporâneo resultante de uma mescla entre liberalismo e utilitarismo, prevê um papel de interventor pontual para o Estado,${ }^{4}$ de modo tal que a economia capitalista globalizada possa atingir níveis máximos de desempenho. Exultantes durante os anos 1990, ante o esfacelamento da experiência do "socialismo real" da União Soviética, autores ditos (neo)liberais chegaram a prever o "fim da história" (Fukuyama, 1989) e a chegada a um consenso global acerca de como administrar a economia (Williamson; Kuczynski, 2003). Pierre Bourdieu (1998) emparelha o novo projeto liberal ao velho marxismo, no que ambos suscitam grandes utopias. Em termos práticos, Bourdieu dirá que o fundamento último desta ordem econômica (internacional) neoliberal é a violência estrutural do desemprego, da precariedade trabalhista e da ameaça embutida: a condição para o funcionamento "harmonioso" do modelo microeconômico individualista é a existência de um exército de reserva de desempregados.

O peso das instituições internacionais na regulação da economia internacional. Se o pensamento marxiano impôs às instituições sociais a condição de epifenômeno - manifestação secundária do fenômeno (primário) das relações produtivas -, Weber (1997) as "descobriu". Weberianamente falando, as instituições deixam de estar submetidas causalmente à atividade econômica. Em que pese o anacronismo da expressão, o autor prussiano é um "institucionalista", no sentido de que, para ele, as instituições importam, porque modelam comportamentos e condutas. Sua ampla teorização sobre a modalidade burocrática da dominação [Herrschaft] pode lastrear o afirmado. Nos dias de hoje, os institucionalistas fazem-se presentes tanto na política e na sociologia quanto na economia e nas relações internacionais. Lisa Martin (1999), por exemplo, identifica na emergência e disseminação das instituições econômicas internacionais o reflexo de escolhas racionais dos governantes estatais. Dentro de uma perspectiva dita "problem-solving”, as instituições

\footnotetext{
${ }^{4} \mathrm{O}$ Estado deve operar como um facilitador da atividade empresarial - omitindo-se, sempre que necessário ou conveniente para o propósito de mercado.
} 
são criadas para coordenar a economia internacional, mitigando a dificuldade acarretada pela condição de "anarquia sistêmica". Importante, no entanto, é perceber que as instituições podem fortalecer-se ou enfraquecer-se em virtude não apenas do cálculo custo/benefício feito pelos atores, senão também em razão da chamada "dependência de trajetória" [path dependence]. Essa noção vem do institucionalismo histórico, corrente que considera as afetações exercidas por variáveis processuais e procedimentais sobre o processo decisório via instituições formais. Desenvolvendo um raciocínio assemelhado ao do estruturacionismo giddensiano, Cox (1996) proporá que as instituições internacionais, embora resultantes da concertação de vontades entre os mais importantes atores de uma determinada configuração espacial e temporal, constituem-se também em espaços (loci) para a revisão/reestruturação da própria ordem que ajudam a sustentar. Logo, em se adotando essa linha de pensamento, resulta equivocado apostar numa relação unilateral de modelagem da ordem econômica internacional pelas instituições. O autor cita o exemplo do movimento pela Nova Ordem Econômica Internacional (NOEI), articulado na Assembléia Geral da ONU durante os anos 1970, o qual se serviu do palanque de uma organização internacional não para reforçar o status quo, mas para buscar, como o seu nome indicava, uma ordem econômica internacional diferente da então vigente.

A "lógica” do mercado internacional. Embora uma instituição milenar (ver Polanyi, 2000), o mercado - concebido como o espaço de trocas - internacional contemporâneo dificilmente poderá ser desatrelado do capitalismo. O sistema econômico que tem por princípio a acumulação do capital assumiu um protagonismo tamanho que, hoje em dia, faz-se difícil encontrar-lhe uma alternativa. ${ }^{5} \mathrm{O}$ número crescente de organizações internacionais em favor do livre-mercado (OMC e FMI, por exemplo), de regimes de cooperação econômica e de blocos econômicos regionais, a difusão da lex mercatoria e dos mecanismos de arbitragem para resolução de controvérsias empresariais, a enorme mobilidade de capital e de mercadorias, seguida do enorme fluxo de remessas internacionais, a profusão de reformas estruturais do Estado na direção do mercado etc., sinalizam a disseminação do mercado como princípio organizador da vida econômica internacional. Mesmo que os antigos teóricos do imperialismo (Lênin, Hobson, Kautsky) já antevissem que "o capital não conhece fronteiras", aparenta que a escala e a intensidade com que se deu a penetração do princípio da "economia de mercado" mundo afora não tem precedente histórico. Chega a invadir o reino da política, conforme sugeriu Schumpeter em sua "teoria econômica da democracia". Para os schumpeterianos, a própria plataforma de governo do candidato em um pleito democrático, ou do político profissional no exercício do mandato, passa a balizar-se exclusivamente pelo cálculo custo/benefício. Essa "lógica” do mercado, segundo Jon Elster (1997), vem do

\footnotetext{
${ }^{5}$ Quando muito, algumas graduações ao princípio, malgrado a existência de ideias e experimentos promissores na direção contrária à da economia de mercado.
} 
entendimento de que a modalidade principal de interação social é a barganha, e não a argumentação ética. Se ela realmente prevalecer, pode acontecer de até as instâncias de natureza eminentemente pública (no caso, as burocracias internacionais, as cortes internacionais etc.) mostrarem-se contaminadas pela racionalidade instrumental do capitalismo global.

Outros aspectos da economia internacional contemporânea. Um desafio consistente à ideia de ordem econômica internacional é captado por Hall e Biersteker (2002), na alegação de que há, contemporaneamente, a emergência de focos de autoridade privada em meio a um quadro geral de governança global (cf. também: Kahler; Lake, 2003). Tais focos são representados, em larga medida, pelas grandes empresas privadas multinacionais, que pressionam Estados e sociedades pela consecução de seus objetivos financeiros. As firmas internacionais passam a estabelecer regimes de cooperação e/ou competição à revelia dos mecanismos regulatórios formais, construindo uma "ordem" inerentemente instável, precária, errática. Isso se deve, também, ao fato de que, com o ingresso na era da comunicação instantânea e dos baixos custos operacionais, aumenta sobremaneira a velocidade dos fluxos de capital - alterando-se muito rapidamente, por conseguinte, a própria geografia econômica internacional. Cidades são incluídas ou excluídas do circuito produtivo global num piscar de olhos (Ong, 2006; Sassen, 2006). Outra constatação que coloca em xeque a noção de ordem econômica internacional é a que dá conta da existência de uma intensa e muito lucrativa atividade econômica ilícita no mundo contemporâneo (Naím, 2006; Biersteker; Hall, 2002), o que dificulta, se não inviabiliza, qualquer perspectiva de ordenação formal das relações econômicas entre Estados e/ou atores não-estatais. Mas se há um campo em que a ordem econômica ainda é efetivamente ditada por Estados, essa é a monetária. Apesar de a globalização ter avançado uma agenda de descentralização e flexibilização dos controles governamentais sobre a economia - doméstica e internacional -, continuamos a viver em um mundo de moedas nacionais (Cohen, 2003). Para mais, existem Estados que vêm conseguindo aplicar seletivamente o consenso neoliberal em seus territórios, como parece ser o caso dos Tigres Asiáticos; mas não de outras partes do mundo (Ong, 2006). No que concerne às organizações internacionais do campo econômico e do trabalho, nota-se considerável capacidade de influenciar as relações entre os Estados, padronizando-lhes as condutas (Barnett; Finnemore, 2004; Patomäki, 2001).

Após procedermos com a discussão sobre a dimensão econômica de uma possível ordem internacional, resta em aberto a questão do multilateralismo e a sua capacidade de emoldurar a atual economia internacional. Cabe falarmos de uma "ordem econômica internacional multilateral"? Ou seria essa apenas mais uma expressão empregada sem o devido rigor pela academia e meios de imprensa? Por entendermos ser o estudo da instituição do multilateralismo contemporâneo uma das etapas cruciais para atestar (ou não) a viabilidade da construção conceitual "ordem econômica internacional”, convém a ela dedicar a próxima seção do trabalho. 


\section{MULTILATERALISMO: DERIVAÇÃO LÓGICA DA ORDEM ECONÔMICA INTERNACIONAL?}

Em artigo intitulado "Multilateralism and World Order" [1992], Robert Cox assim se pronuncia:

The two concepts [multilateralism and world order] are interrelated. Multilateralism appears in one aspect as the subordinate concept. Multilateralism can only be understood within the context in which it exists, and the context is the historical structure of world order. But multilateralism is not just a passive, dependent activity. It can appear in another aspect as an active force shaping world order (Cox, 1996: 494, grifo nosso).

Note-se, em primeiro lugar, a afirmação de que multilateralismo e ordem mundial estão inter-relacionados. O autor não hesita em propor uma imbricação entre os dois conceitos, sem o que não há ordem mundial nem multilateralismo. Em outras palavras, Cox parece lidar com uma díade: falar em ordem mundial na contemporaneidade implica trazer a reboque a categoria do multilateralismo, e vice-versa.

Mais adiante, o autor expõe o fundamento de seu raciocínio. Supõe existirem dois tipos de multilateralismo: o econômico, ou seja, os processos das estruturas econômicas globais liberais sustentados pelos Estados capitalistas mais poderosos; e o político, ou a aspiração ao controle consensual sobre os processos econômicos globais que venham fortalecer os países menos desenvolvidos (como na demanda terceiro-mundista por uma "Nova Ordem Econômica Internacional", nos anos 1970). O multilateralismo político é, pois, uma decorrência (mas não uma determinação) do multilateralismo econômico. Existe certa "ascendência causal" da segunda subcategoria sobre a primeira, por assim dizer.

Fica evidenciado, ao retomar-se a concepção de ordem mundial de Cox, que se trata de uma aplicação de seu arcabouço teórico à conjuntura do início dos anos 1990. A ordem mundial possível, hoje, é condicionada por estruturas econômicas e forças sociais. Donde a necessidade, e não apenas a adequação ou a plausibilidade, de reconhecimento de um conceito tal como o de ordem econômica internacional multilateral.

Há, no entanto, farta controvérsia a respeito. Sobretudo porque, ao tomar o multilateralismo como instituição da política internacional contemporânea, Cox não problematiza o conceito, dando por suposto o seu sentido. $\mathrm{O}$ autor limita-se a citar organizações internacionais multilaterais, com ênfase na Organização das Nações Unidas e em suas agências especializadas. Atém-se à descrição de casos, pretensamente ilustrativos de determinados fenômenos da ordem mundial. Em vista disso, pergunta-se: a rigor, em que medida a ONU é uma instituição multila- 
teral? $\mathrm{Ou}$, ainda: existe multilateralismo de facto na atual composição das relações internacionais?

Para responder às questões a contento, faz-se necessário abstrair, na tentativa de formulação de uma definição operacional de multilateralismo. Com base, principalmente, no chamado institucionalismo sociológico, John Ruggie (1998) tenta desenvolvê-la. Contrapondo-se à abordagem meramente nominal de Robert Keohane, ${ }^{6}$ Ruggie resgata alguns dos sentidos que o multilateralismo assumiu ao longo da história, desde a experiência da Liga das Nações. Afirma que "multilateral" sempre é um adjetivo que modifica o substantivo "instituição" - e que, portanto, os termos não podem ser tomados como complementares ou coextensivos. A definição de multilateralismo que Ruggie oferece é a seguinte:

Multilateralism is an institutional form which coordinates relations among three or more states on the basis of 'generalized' principles of conduct - that is, principles which specify appropriate conduct for classes of actions, without regard to the particularistic interests of the parties or the strategic exigencies that may exist in any specific occurrence (Ruggie, 1998: 109, grifo nosso).

A elaboração conceitual apoia-se em dois pontos-chave: (1) na indivisibilidade, ou seja, o imperativo moral (mas não físico) de que haja isonomia no tratamento recebido por todos os membros de um arranjo coletivo, sem exceção ou compartimentalização; e (2) na "reciprocidade difusa", isto é, a expectativa de que todos os membros de uma organização multilateral sejam igualmente beneficiados ao longo do tempo. O próprio autor reconhece tratar-se de uma forma institucional altamente demandante - e que, por isso, seria menos frequente no curso da história. Nesse sentido, o século XX representaria a "descontinuidade". O corolário da argumentação, trazido para o contexto da discussão, é a discordância de Ruggie da análise de Cox, porquanto nem toda ordem econômica internacional há de ser multilateral. ${ }^{7}$ Muito pelo contrário: levando-se em conta a trajetória histórica estudada, o multilateralismo é antes a exceção, e não a regra (cf. Ruggie, 1998, 1993; mas também Ikenberry, 2001).

Talvez seja na dimensão da economia internacional que mais se pronuncie a dificuldade de concretização do multilateralismo preconizado por Ruggie. Kahler (1992), a partir do seu trabalho empírico com experimentos multilaterais contendo variável número de participantes, lançou algumas ideias relevantes no debate. $\mathrm{O}$ autor abdicou, de início, de uma definição "espessa” de multilateralismo em prol de uma minimalista. Multilateralismo, em sua elaboração, é “international governance of the

\footnotetext{
${ }^{6}$ Autor cuja definição de multilateralismo consiste na "prática de coordenar políticas nacionais em grupos de três ou mais Estados” (Keohane apud Ruggie, 1998: 105).

${ }^{7}$ Segundo o autor, as ordens internacionais também podem ser imperiais ou bilaterais.
} 
many" (1992: 681). Por meio do instrumental da teoria da ação coletiva olsoniana, Kahler passa a notar as dificuldades envolvidas na cooperação efetiva "com grandes números", ou seja, nos fóruns internacionais multilaterais. Adiante, a respeito das relações econômicas internacionais, assinala: "the organization of international economic relations frequently demonstrated the same mixture of a multilateralism supported by great power collaboration and diluted by bilateralism” (p. 687).

$\mathrm{O}$ autor postula existir um gargalo entre o multilateralismo "conceitual" - à moda de Ruggie - e as práticas que dele decorrem (especialmente, na dimensão econômica da ordem internacional). O descompasso é exemplificado pela análise que Kahler desenvolve sobre o regime contemporâneo de comércio internacional, nascido sob o impacto da Carta do GATT (uma das instituições multilaterais de Bretton Woods):

$[\mathrm{I}] \mathrm{n}$ the trade regime that emerged [...] one could perceive most clearly by the 1960s the minilateral core of a regime that embodied both multilateral principles and limitations on those principles. The careful hedges in the GATT system also reflected a world in which the great powers still preferred bilateralism for at least some of their trading relationships (Kahler, 1992: 688, grifo nosso).

Em face de fenômenos políticos tais como a mobilização, via ONU, de um bloco terceiro-mundista a favor da NOEI, as potências capitalistas - com destaque para os Estados Unidos da América - começaram a empregar diferentes técnicas para lidar com os que pretendiam valer-se da simples maioria numérica nos foros multilaterais para impor os rumos. É quando se firma a noção de "minilateralismo”. Kahler nota, através de seus estudos relativos à Rodada Uruguai do GATT, à III Conferência da ONU sobre o Direito do Mar e aos regimes globais sobre o meio ambiente, a emergência de um padrão de interação multilateral, consistente no estabelecimento de "clubes dentro do clube". Em outras palavras, Estados passam a associar-se em blocos, conforme os seus interesses mais imediatos, rompendo com o "princípio da indivisibilidade" de Ruggie (vide os casos de G-77, G-8, G-20, G-90; e a recente proliferação das abordagens negociais "case-by-case" em lugar do "single undertaking"). Miles Kahler argumenta convincentemente, fundado nos dados empíricos levantados, que:

In certain issue-areas, such as international monetary affairs and economic policy coordination, it is likely that great power minilateralism will continue to dominate, since the collaboration of lesser economic powers is neither necessary nor desirable from the point of view of the United States, Japan and the European Community (Kahler, 1992: 707, grifo nosso).

Relembrando uma categoria aristotélica, constante na Retórica, o questionamento a fazer é o seguinte: o multilateralismo é a consequência lógica de uma 
(suposta) concertação econômica internacional, ou, ao contrário, a ideia de "ordem econômica internacional multilateral" constitui o que se poderia chamar de entimema erístico ${ }^{8}$ À luz da discussão pregressa, que contrapõe o conceitualismo de Cox (1996) e de Ruggie (1993, 1998) ao empirismo de Kahler (1992), fica sugerida a conclusão de que, mesmo em se considerando plausível a categoria da "ordem econômica internacional”, dificilmente se poderá adjetivá-la de multilateral - independentemente de ser a concepção de multilateralismo mobilizada a maximalista de Ruggie ou a minimalista de Kahler. Portanto, este seria, em nossa opinião, mais um dentre os tantos casos de entimema erístico que permeiam o mainstream da produção acadêmica contemporânea, seja em economia política, seja em relações internacionais. A rigor analítico, ainda não existe uma ordem econômica internacional multilateral de facto.

\section{CONCLUSÃO: ORDEM ECONÔMICA INTERNACIONAL - ASSIM É, SE LHE PARECER}

A tentativa de identificar um padrão organizacional abrangente, que explique as relações econômicas internacionais em toda a sua complexidade, parece fadado ao insucesso. Porém, ao que se nos afigura, se abdicarmos da tentação de uma abordagem totalizante do tema em favor de uma análise fracionada, menos ambiciosa, as perspectivas mostram-se mais encorajadoras.

Resumidamente, alguns dos prováveis elementos constituintes de uma ordem econômica internacional foram colocados em discussão no corpo deste trabalho. Atestou-se, dentre outros, (1) a dificuldade de esquematizar-se uma divisão internacional do trabalho, considerada a natureza mutante e fragmentária da geoeconomia mundial. Sob a globalização, torna-se contraproducente permanecer atado a categorias dicotômicas tais como "Sul e Norte", "desenvolvidos e subdesenvolvidos", "Primeiro Mundo e Terceiro Mundo". Muito da produção industrial mais intensiva em intelecto no mundo de hoje vem de países cujos índices de desenvolvimento humano estão entre os mais baixos (vide os casos de Índia e China). (2) No que toca à relação entre a economia e o Estado (ou entre a economia internacional e o sistema internacional), a ambiguidade prevalece. Não cabe apontar um padrão unívoco, já que os indícios coletados são ambivalentes e, portanto, inconcludentes. Observem-se, por exemplo, as diferentes respostas dadas pelos Estados da América Latina e do Sudeste Asiático aos desafios impostos pela globalização

\footnotetext{
${ }^{8}$ Entimema é o silogismo em que uma premissa, considerada evidente ou de conhecimento geral, vem omitida. O adjetivo "erístico" é uma alusão ao emprego desse recurso retórico, feito usualmente pelo sofista, que deixa, estrategicamente, de externar a "premissa oculta”, transformando uma relação entre proposições que não foi efetivamente demonstrada (porquanto estava "subentendida") em um silogismo perfeito.
} 
econômica, no curso dos anos 1990. Se existe um substrato liberal na economia internacional, ele é incorporado e manifesto de formas muito variadas ao redor do mundo. Além, (3) faz-se perceptível uma presença (ainda) muito forte do Estado na regulação de economias nacionais (vide o protecionismo agrícola de tanta repercussão na OMC; ou as políticas monetárias conservadoras dos Estados que hesitam em aderir à "Zona do Euro") - o que, em vários pontos, contraria o credo (neo)liberal. (4) A influência das instituições internacionais sobre a economia internacional é, de um modo geral, discutível - embora notória e apreciável em certos setores e sob determinadas circunstâncias. (5) A "lógica" capitalista das relações econômicas internacionais é quase um ponto pacífico; mesmo que certos movimentos da sociedade civil global - o Fórum Social Mundial é um exemplar importante - reivindiquem que "um outro mundo é possível". Por fim, constatamos que (6) a emergência de novos atores e processos nas relações internacionais tem servido de fator de indefinição/incerteza/imprevisibilidade na composição de uma pretensa “ordem” econômica mundial.

Fica, por fim, a impressão de que a proposição, sem cotejo, da existência de uma ordem econômica internacional no mundo presente pode soar - diante das ressalvas que se vêm fazendo - um tanto temerária. Embora se deva conceder determinados indícios de ordenação da conjuntura econômica internacional atual e.g., a construção concomitante dos blocos econômicos regionais; o movimento coordenado das grandes bolsas de valores do mundo; ou a padronização na maneira como as agências de rating "percebem" o grau de risco de investimento nos mercados emergentes -, importa ressaltar que se trata de elementos pontuais em um mar de ambiguidades. Mais recomendável seria, considerado o mote deste artigo, fazer descrição analítica do objeto de estudo, que pudesse sublinhar traços de continuidade ou de ruptura na atividade econômica internacional, e abrir mão da pretensão de integralidade/sistemicidade/universalidade. Levando ao limite este argumento, poder-se-á afirmar que a ordem econômica internacional consiste em uma poderosa utopia, em um momentoso não-lugar das relações internacionais contemporâneas. Não obstante, ela permanece presente - e bastante influente - nas narrativas teóricas e jornalísticas, ostentando a inabalável condição de premissa.

\section{REFERÊNCIAS}

BARNETT, M. \& Finnemore, M. (2004), Rules for the world. Ithaca and London: Cornell University Press.

BIERSTEKER, T. \& Hall, B. R. (2002), The emergence of private authority in global governance. Cambridge: Cambridge University Press.

BOURDIEU, P. (1998), “L'essence du néoliberalisme”, Le Monde Diplomatique, mars 1998, p. 3. . (1997), "Le champ économique", ARSS, n. 119, septembre 1997, p. 48.

BULL, H. (1995), The Anarchical Society. New York: Columbia University Press.

COHEN, B. (2003), "Monetary Governance in a World of Regional Currencies" in Kahler, M. \& Lake, D., op. cit. 
COX, R. W. (1986), "Social forces, states and world orders: beyond international relations theory" in Keohane, Robert. O. (ed.), Neorealism and its critics. New York: Columbia University Press. (1996), Approaches to world order. Cambridge: Cambridge University Press.

DOYLE, M. W. (1999), “A liberal view: preserving and expanding the liberal pacific union" in Paul, T. V. \& Hall, J. A. (ed.), International Order and the Future of World Politics. Cambridge: Cambridge University Press.

ELSTER, J. (1997), "The market and the forum: three varieties of political theory" in Bohman, J. \& Rehg, W. (ed.), Deliberative Democracy: Essays on Reason and Politics. Cambridge, Mass. and London: The MIT Press, pp. 3-33.

FUKUYAMA, F. (1989), “The end of history?”, The National Interest, summer 1989.

GIDDENS, A. (2003), A constituição da sociedade. São Paulo: Martins Fontes.

HUNT, E. K. (2005), História do pensamento econômico. Rio de Janeiro: Campus.

IKENBERRY, J. (2001), After victory. Princeton: Princeton University Press.

KAHLER, M. (1992), "Multilateralism with small and large numbers", International Organization, Vol. 46, No. 3. (Summer, 1992), pp. 681-708.

. \& Lake, D. (2002) (ed.), Governance in a global economy. Princeton: Princeton University Press.

MARTIN, L. (1999), “An institutionalist view: international institutions and state strategies” in Paul, T. V. \& Hall, J. A., op. cit.

NAÍM, M. (2006), Ilícito. Rio de Janeiro: Jorge Zahar Editor.

ONG, A. (2006), Neoliberalism as exception. Durham and London: Duke University Press.

PATOMÄKI, H. (2001), Democratizing Globalization. London: Zed Books.

PLATÃO (2001), República. São Paulo: Martin Claret.

POLANYI, K. (2000), A grande transformação. Rio de Janeiro: Campus.

RUGGIE, J. (1993) (ed.), Multilateralism matters. New York: Columbia University Press. . (1998), Constructing the world polity. New York: Routledge.

. (1983), "International regimes: transactions and change; embedded liberalism in the postwar economic order" in Krasner, S. (ed.), International regimes. Ithaca: Cornell University Press.

SARAIVA, F. R. S. (2006), Dicionário latino-português. Belo Horizonte: Livraria Garnier.

SASSEN, S. (2006), Territory, authority, rights. Princeton: Princeton University Press.

SENNETT, R. (2006), A cultura do novo capitalismo. Rio de Janeiro: Record.

SMELSER, N. \& Swedberg, R. (1994) (ed.), The handbook of economic sociology. New York: Russell Sage Foundation; Princeton: Princeton University Press.

WALKER, R. B. J. (1993), Inside/outside. Cambridge: Cambridge University Press.

WALLERSTEIN, I. (1979), The capitalist world economy. Cambridge: Cambridge University Press. . (1996), "The inter-state structure of the modern world-system" in Smith, S. et alii (ed.), International theory: Positivism and beyond. Cambridge: Cambridge University Press.

WALTZ, K. (1979), Theory of international politics. New York: McGraw-Hill, Inc. . (2004), O homem, o Estado e a guerra. São Paulo: Martins Fontes.

WEBER, M. (1997), Economia y Sociedad: Esbozo de Sociologia Compreensiva. Ciudad. de México: Ed. Fondo de Cultura Económica.

WILliAMSON, J. \& Kuczynski, P. P. (2003) (ed.), After the Washington Consensus: Restarting Growth and Reform in Latin America. Peterson Institute.

WOLIN, S. (1960), Politics and vision: continuity and change in Western political thought. New York: Little Brown and Co. 